\title{
Forward - Looking Monetary Policy and the Contributions of Public Expectations
}

\author{
Raul Cruz Tadle \\ California State University, Sacramento
}

\begin{abstract}
Board of Governors staff present macroeconomic forecasts to FOMC members shortly before scheduled policy meetings, but only releases these forecasts to the public after five years. To examine if policy rate decisions depend solely on these forecasts, I analyze whether or not information similar to publicly available economic outlook affect policy decisions. Moreover, I use Semi-Automated Content Analysis on FOMC meeting statements to evaluate the type of forecasts reflected in these statements. I find that publicly available inflation projections and contemporaneous staff forecasts of unemployment best portray macroeconomic information that affects policy while FOMC statements are consistent with staff projections.
\end{abstract}

Keywords: federal reserve, monetary policy, statements, macroeconomic forecasts

\section{INTRODUCTION}

Conventional monetary policy, as determined by the Federal Open Market Committee (FOMC), is largely dependent on the control over the Federal Funds rate. The target levels for the fed funds rate, particularly those that are unexpected, have significant impact on financial markets and these effects can then transmit to the real economy. To guide market expectations regarding monetary policy, the FOMC has released statements on the same day as the meetings to announce the policy target as well as to discuss economic indicators that have influenced the committee's decision. These policy statements have received much attention as they not only change policy expectations but also influence expectations about the economy.

As the FOMC determines what rate to set and what economic information to communicate, it utilizes a tremendous amount of resource in order to obtain some of the most accurate estimates not only of current macroeconomic variables, such as the output growth and inflation, but also the values that these variables may have over time. These projections are prepared by the Federal Reserve (Fed) staff and, until 2009, are stored in what is known as the Greenbook. Beginning in 2010, the forecasts in the Greenbook are instead placed in a document called the Tealbook. These staff projections are only released to the public after five years.

Given the restrictions in access to the staff forecasts, the public, which also forms expectations about the nominal interest rate that the FOMC may take, have to rely on other macroeconomic projections that are publicly available. These projections, such as the Survey of Professional Forecasters (SPF), are good proxies for staff forecasts for short horizons but are inferior in longer horizons (Romer and Romer (2008)). Given the importance of forecasts to monetary policy decisions, I evaluate two points of inquiry. First, I determine whether the FOMC depends solely on the staff forecasts or if the FOMC also examines 
information similar to the forecasts available to the public. In this examination, I evaluate whether models incorporating publicly available economic projections are better suited to estimate the policy rate than those that depend completely on staff forecasts. My other inquiry analyzes the information contained in the statements released shortly after FOMC meetings. I assess whether the discussions in these documents convey additional information beyond those that are publicly available.

Evaluating whether public forecasts reflect information considered during FOMC meetings is relevant since the information conveyed by public forecasts helps the private sector determine its business decisions and policy expectations. If the FOMC members do not account for information that is more similar to widely available forecasts, then public expectations about monetary policy may differ significantly from the actual rate implemented by the Fed. Following this train of thought, my findings indicate that the FOMC's conventional policy decisions are most consistent with a combination of publicly available forecasts of inflation and staff projections of unemployment.

My second point of inquiry evaluates the information in the policy statements. Given that much attention is focused on these documents, I evaluate which type of economic forecasts more closely convey the information in the statements. I conduct Semi-Automated Content Analysis in order to decipher the information sentiments of these documents. I find that my document sentiment index is more consistent with the staff forecasts of inflation and unemployment than with the comparable SPF projections.

The rest of the paper is structured as follows. Section 2 discusses the motivation and related literature regarding FOMC policy determination. Section 3 elaborates on the forecast data and conducts rationality tests comparing staff forecasts to publicly available forecasts. Section 4 then evaluates the type of economic projections that more closely resemble economic data used for the policy rate optimization. Section 5 explains the Semi-automated content analysis approach that calculates the statement sentiment index; it also determines which of the forecasts are more consistent with the statement sentiments. Finally, section 6 presents some robustness and extensions to the empirical evaluation while section 7 concludes with some remarks.

\section{MOTIVATION AND RELATED WORK}

\section{Related Literature}

Many papers have studied how central bankers optimize monetary policy, usually by assuming a monetary policy rule that incorporates observations of relevant macroeconomic fundamentals. The most prominent of these policy rules is the Taylor rule. It has been modified in several ways, but each empirical formulation incorporates a variant of inflation as one of the arguments in the policy rule.

Taylor (2012) indicates that the Fed has closely resembled the policy recommendations of the Taylor Rule in the 1980s. He then explains that deviations from this policy ruling began to significantly increase by the early 2000s. Nikolsko-Rzhevskyy et al. (2014) evaluates the difference between the Taylor prescriptions and actual policy and found evidence of a structural break from a Fed regime with smaller deviations to the Taylor Rule to another with large deviations around this period.

Ben Bernanke addressed this deviation during his 2010 American Economic Association Speech. He indicated that the Fed seemed to have deviated away from the recommendations of the Taylor rule; however, he explains that the Fed has not followed any policy rule and has been forward-looking when setting monetary policy. While reiterating this point, Bernanke pointed out that when conducting a comparative analysis between Fed policy decisions and the prescriptions of a policy ruling, a forwardlooking policy rule would be more appropriate.

Still, Kahn (2010) argues that failing to follow the prescriptions of the Taylor Rule could be suboptimal since not following these prescriptions can lead to adverse effects in the economy. He explains that such deviations may have resulted in varying financial imbalances, especially in terms of house prices relative to rental costs. He argues that house prices rose significantly when rates were lower than recommended since house financing was cheaper than they should have been. He also shows that the lagged Taylor Rule deviations seem to help predict housing price bubbles, thereby pointing to the potential negative effects of setting the policy rate lower than what is prescribed by the Taylor Rule. 
Considering the arguments made by Kahn (2010), it is important to examine the reasons why the Fed does not follow a policy ruling - particularly, the Taylor Rule. Walsh (2001) explains that the Fed does not follow monetary policy prescriptions since "conducting policy is far from routine." It is necessary for the Fed to undertake quantifiable guidance, much of which is not incorporated in the general principles of proposed monetary policy rules. In addition, if a particular monetary policy ruling is to be adopted, it must be dynamic as policymakers determine the best course of policy based on the fluctuating conditions of inflation, unemployment, output, and other economic variables. This implies that the adopted rule must change as different economic variables vary in importance. As a result, a static policy setting is insufficient in determining the best policy rate to implement.

Walsh (2001) also argues that when deciding the appropriate policy rate, the Fed must consider not only the best estimates of macroeconomic variables in the current period but also how policies will affect them. Observing the current as well as the future outlook of the economy is therefore relevant given that the full effects of changes in monetary policy on economic variables are realized typically with a lag. When considering the future economic outlook, the Federal Open Market Committee (FOMC), which determines the course of U.S. monetary policy, relies on the best available information as well as the most accurate forecasts of the economy.

Orphanides and Wieland (2008) examine whether the policy rates set by the FOMC can be explained by the projections of relevant macroeconomic variables. They extrapolate from the Monetary Policy Reports the forecasts that FOMC members have for these variables. They find that unlike the prescriptions given by the Taylor Rule which depend on observed outcomes, observed monetary policy is more consistent with forecast-based rules.

When considering economic projections available to the FOMC, the most notable are those prepared by the staff of the Board of Governors (BOG). The staff members prepare forecasts for different macroeconomic variables and their projections begin from the current period up to several quarters ahead. ${ }^{2}$ A significant amount of resources ensures that these are as accurate as possible. For this reason, Romer and Romer (2000) and El-Shagi et al. (2014) find that the BOG staff projections are superior to commercial forecasts for farther-ahead horizons.

\section{FOMC Member vs. Board of Governors Staff Forecasts}

Despite having access to staff forecasts, FOMC members create projections - as reported in the Monetary Policy Reports to Congress - that sometimes deviate from staff forecasts (Romer and Romer (2008)). Several reasons may explain these differences. First, the Federal Reserve regional presidents, who have rotating voting seats in the FOMC, uses different forecast models than those utilized by the BOG staff. These models incorporate their expectation formation and reflect the difference in beliefs among the BOG staff and the Fed presidents.

Another potential reason why the BOG staff and Fed presidents have different forecasts is that the types of economic information they use are different, thereby making the forecasts vary. Moreover, another reason that may explain why the two types of forecasts vary is that the Fed presidents may not only consider the BOG staff forecasts when making their own but may also be consulting information available to the public. This last explanation can lead actual policy to be more consistent with public expectations.

The explanation that assumes that forecast models are significantly different seems unlikely. If either the staff or the regional presidents' forecasts are systematically different from actual observations because of their model specifications, then the Fed presidents, whose forecasts may not be as accurate as argued by Romer and Romer (2008), would have adjusted their forecasting methods to be closer to those of staff forecasts. Given that the staff and Fed president projections are forecasting the same economic indicators, the differences in the models - and by extension, the projections - should have diminished over time.

In addition, the type of economic data that FOMC members use are closely scrutinized by the BOG staff. This is because the staff also makes projections that account for the expected policy implementation. Therefore, it is unlikely that differences in economic variables are causing the variation. 
The most plausible reason for the difference between the regional bank presidents' projections and staff forecasts is that the bank presidents also considers economic information that more closely resembles widely available economic forecasts. The use of this information results in increased agreement between the FOMC's overall view of economic indicators and those of the public. With this consistency, policy expectations deviate less from realized values.

\section{RATIONALITY TESTS}

\section{Data}

To examine whether the implemented policy is based mainly on confidential staff forecasts or if the policy decisions also consider information similar to publicly available projections, I examine staff forecasts for unemployment, inflation, and real gdp growth. I also evaluate the median forecasts for these economic variables from the Survey of Professional Forecasts (SPF) ${ }^{3,4}$ As discussed in the literature, the SPF forecasts serve as a good representation of commercial projections. The collection of these forecasts was formerly conducted by the American Statistical Association and the National Bureau of Economic Research until 1990. It has since been spearheaded by the Federal Reserve Bank of Philadelphia.

As for data on realized values of macroeconomic indicators, I use the monthly Federal Funds Effective Rate and quarterly CPI inflation data from the Federal Reserve Board of St. Louis (FRED), the real GDP growth from the Bureau of Economic Analysis, and the monthly unemployment data from the Bureau of Labor Statistics. ${ }^{5}$ I also utilize the Natural Rate of Unemployment estimates from FRED. The data I collected spans from the initial availability in 1982 when the federal funds rate target was publicly announced to December 2013. The analysis related to the statements, on the other hand, covers the period between May 1999 when the statements have been released regularly to December 2013. ${ }^{6}$

\section{Comparing Forecasts to Actual Observations}

Examining the accuracy of publicly available economic forecasts as well as staff forecasts provides additional insight into the choice of economic indicators that the FOMC ultimately uses. To evaluate the accuracy of the BOG staff and SPF information, I examine how well the forecasts fare compared to the realized values. These forecasts should at least be strongly correlated with the values that they are projecting in order for them to be credible. To conduct rationality tests on the comparisons between the realized values and forecast values of varying horizons, I follow Romer and Romer (2008) and use the specification

$$
A E I_{t, q}=\alpha+\beta F E I^{T O F} F E I_{t, q}^{T O F}+\varepsilon_{t, q}
$$

In equation $1, A E I_{t, q}$ represents one of the realized economic indicators (unemployment, real gdp growth, and CPI inflation), wherein $t$ represents the baseline period and $q$ stands for the number of quarters ahead from $t$ the value is observed. To demonstrate, $A E I_{t, q}=U N E M P_{t, 2}$ indicates the unemployment rate observed two quarters ahead of $t . F E I_{t, q}^{T O F}$ stands for the forecast for $A E I_{t, q}$ based on TOF, the type of forecast source (BOG staff or SPF). ${ }^{7}$

I also evaluate whether $\beta F E I^{T O F}$ is statistically different from 1 . This examination determines whether there is a strong correlation between the forecasts and actual values. Therefore, this set of tests evaluates the accuracy of the forecasts and helps indicate the type that is better able to predict the actual economic indicators.

As shown in Appendix A1, my findings indicate that both the BOG staff and SPF forecasts perform well in projecting unemployment and CPI inflation. These projections are excellent for the nowcasts and closer horizons. They both perform worse when projecting father ahead horizons. 


\section{EMPIRICAL ANALYSIS ON THE FED FUNDS RATE}

\section{Empirical Specification and Results: Fed Funds Rate}

The members of the FOMC receive copies of the staff forecasts about a week before each FOMC meeting. This set of data, however, is available to the public only after a five-year lag and therefore cannot affect the public's expectations in the current period. Despite the superior quality of the staff projections, it is plausible that the FOMC members also consult information that is more similar to those used by private forecasters. They may examine projections that resemble public forecasts to maintain some consistency between the information available widely and those that they utilize in determining monetary policy. This results in the actual policy to be more in line with the public's expectations even if the public has a more limited source of economic forecasts. To evaluate the validity of this argument, my analysis considers both Federal Reserve Staff as well as commercial forecasts to determine whether private sector forecasts release projections similar to the economic information that is vital in determining the Federal Funds target rate.

To evaluate whether monetary policy decisions are decided not only with the Fed's private projections but also with information that is consistent with publicly available forecasts, I examine whether the federal funds rate can be estimated more accurately by a combination of BOG staff and SPF forecasts. When evaluating the federal funds rate, I restrict the time period up to December 2008, when the fed funds rate target is limited by the zero lower bound. When considering the set of forecasts to include, I incorporate the Fed dual mandate objectives of stabilizing prices and maximizing sustainable employment. In terms of accounting for inflation, I follow Orphanides and Wieland (2008) and Romer and Romer (2008) and include its one-year average forecast. ${ }^{8}$ This is calculated as the four-quarter averages of the annualized quarter-to-quarter headline CPI inflation given by

$\bar{\pi}_{t, t+3}^{T O F}=\frac{I N F L A_{t, 0}^{T O F}+I N F L A_{t, 1}^{T O F}+I N F L A_{t, 2}^{T O F}+I N F L A_{t, 3}^{T O F}}{4}$

Using this calculation avoids the problems arising from the forecast errors for inflation and focuses on the predicted level of inflation that occurs a year ahead. Given that unemployment has a more immediate reaction to policy than inflation, I also consider the nowcasts for unemployment. ${ }^{9}$

When examining the impact of forecasts on implemented policy, there are many possible models that can be created with different combinations of the set of forecast variables. To limit the number of models to consider, I use the Leaps and Bounds algorithm created by Furnival and Wilson (2000) and discussed in $\mathrm{Ni}$ and Huo (2006). From the set of possible regression models, the Leaps and Bounds algorithm chooses the optimal subset based on given information criterion. To then choose the most preferred regression model, I consider the suggestions of the Bayesian Information Criterion (BIC). ${ }^{10}$

I compare the BIC-preferred model to the specifications using the projections for unemployment and the four-quarter forecast average for each forecast type as shown by the specification

$r_{t}=\gamma_{0}+\gamma_{U N E M P_{t, 0}^{T O F}} U N E M P_{t, 0}^{T O F}+\gamma_{\bar{\pi}_{t, t+3}^{T O F}} \bar{\pi}_{t, t+3}^{T O F}+\varepsilon_{t}$

Since multicollinearity may be an issue for regression analysis that incorporates forecasts for the same set of economic indicators, I also examine the Variance Inflation Factor (VIF) of each of the regression specifications. The Mean VIF specifies how large the average correlation of the independent variables are for the corresponding regression model. ${ }^{11}$

The results are given in Table 1. Column [1] indicates the results that use only the staff forecasts while column [2] shows the results using SPF forecasts only. The rest of the columns reflect the findings for the combined forecasts following the BIC and AIC suggestions. The coefficient estimates for the nowcasts of unemployment are all negative while the four-quarter average forecasts have positive coefficient estimates. These are consistent with the idea that weaker economic outlook as reflected by higher unemployment leads the FOMC to conduct expansionary monetary policy. On the other hand, with 
higher inflation outlook, the FOMC is more likely to implement contractionary policy to lower these inflationary pressures. Examining the suggestions of the BIC, I find that the most preferred specification for the federal funds rate includes a combination of BOG staff unemployment nowcasts and the four quarter average inflation forecasts provided by the SPF. The coefficient estimates for the included covariates are significant at the 5\% level and have signs consistent with how the Fed responds to economic indicators. ${ }^{12}$

\section{TABLE 1 \\ REGRESSION RESULTS WITH COMBINATIONS OF FORECASTS}

\begin{tabular}{|c|c|c|c|c|}
\hline \multirow{2}{*}{ Independent Variables } & \multirow{2}{*}{$\begin{array}{c}\text { Staff Only } \\
{[1]}\end{array}$} & \multirow{2}{*}{$\begin{array}{c}\text { SPF Only } \\
{[2]}\end{array}$} & \multicolumn{2}{|c|}{ Combined Forecasts } \\
\hline & & & $\begin{array}{l}\mathrm{BIC} \\
{[3]}\end{array}$ & $\begin{array}{c}\text { AIC } \\
{[4]}\end{array}$ \\
\hline$U N E M P_{t, 0}^{\text {Staff }}$ & $\begin{array}{c}-0.44 * * * \\
(0.07)\end{array}$ & & $\begin{array}{c}-0.43 * * * \\
(0.06)\end{array}$ & $\begin{array}{c}-0.43 * * * \\
(0.06)\end{array}$ \\
\hline $\bar{\pi}_{t, t+3}^{\text {Staff }}$ & $\begin{array}{c}2.01 * * * \\
(0.10)\end{array}$ & & & $\begin{array}{l}0.52^{*} \\
(0.30)\end{array}$ \\
\hline$U N E M P_{t, 0}^{S P F}$ & & $\begin{array}{c}-0.42 * * * \\
(0.06)\end{array}$ & & \\
\hline $\bar{\pi}_{t, t+3}^{S P F}$ & & $\begin{array}{c}2.47^{* * *} \\
(0.10)\end{array}$ & $\begin{array}{c}2.46^{* * *} \\
(0.10)\end{array}$ & $\begin{array}{c}1.88^{* * *} \\
(0.34)\end{array}$ \\
\hline Constant & $\begin{array}{c}1.69 * * * \\
(0.53)\end{array}$ & $\begin{array}{l}-0.09 \\
(0.51)\end{array}$ & $\begin{array}{l}-0.04 \\
(0.51)\end{array}$ & $\begin{array}{c}0.25 \\
(0.55)\end{array}$ \\
\hline$R^{2}$ & 0.72 & 0.76 & 0.76 & 0.77 \\
\hline $\mathrm{N}$ & 251 & 251 & 251 & 251 \\
\hline Root MSE & 1.59 & 1.47 & 1.47 & 1.46 \\
\hline f-stat p-value & 0 & 0 & 0 & 0 \\
\hline Mean VIF & 1 & 1 & 1 & 6.32 \\
\hline
\end{tabular}

Note: $* * *$ indicates significance at the $1 \%$ level, $* *$ signifies significance at the $5 \%$ level, and * indicates significance at the $10 \%$ level. The values in parentheses are robust standard errors. The analyses include all of the FOMC meetings in the period from October 1982 to December 2013. The dependent variable is the average effective federal funds rate for the month during which the meeting was held.

The most plausible explanation for why the preferred specification includes a combination of staff and SPF forecasts is that the FOMC also observes economic information that is similar to the projections of macroeconomic variables available to the public, particularly those for inflation forecasts. This finding increases the consistency between the FOMC's policy and the public's policy expectations. It also affirms the position expressed by Bernanke et al. (2007) who indicate that the FOMC's “... ability to forecast inflation and predict how inflation will respond to policy actions depends very much on our (the FOMC's) capacity to measure and to understand what determines the public's expectations of inflation."

\section{Comparing the Suggested Model to the Prescriptions of the Taylor Rule}

The Taylor Rule has been used as a benchmark comparison for monetary policy. As indicated earlier, several papers argue that there are potential economic effects following large deviations from the values prescribed by this rule. For instance, Taylor and Bean (2010) argue that having the policy rate lower than 
the level prescribed by the Taylor Rule resulted in the housing bubble and contributed to the emergence of the Great Recession. However, the FOMC has indicated that it does not follow any policy rule and has depended on economic outlook when deciding which policy is best to implement. Comparing the implemented policy to those prescribed by the Taylor Rule as well as to those estimated using economic forecasts is insightful in evaluating if using forecasts is better at explaining FOMC decisions compared to the Taylor Rule.

In order to make the comparisons, I use the original policy rule as described by Taylor (1993):

$r_{t}^{\text {Taylor }}=2+\bar{\pi}_{t-3, t}+0.5\left(Y_{t}-Y_{t}^{*}\right)+0.5\left(\bar{\pi}_{t-3, t}-2\right)$

where $Y_{t}$ represents real GDP and $Y_{t}^{*}$ stands for the real GDP trend. Hence, $Y_{t}-Y_{t}^{*}$ represents the output gap. Moreover, $\bar{\pi}_{t-3, t}$ represents the annual inflation rate from the period year. I also include the Rule of Thumb (ROT) policy rule as used in Elias et al. (2014) for comparison. Invoking Okun's law, the ROT policy rule is a version of the Taylor Rule that includes the unemployment gap instead of the output gap as follows ${ }^{13}$ :

$r_{t}^{R O T}=1.25+1.5 \bar{\pi}_{t-3, t}^{S P F}-2\left(U N E M P_{t, 0}^{S P F}-U N E M P_{t, 0}^{*}\right)$

In the ROT rule, $U N E M P_{t, 0}^{*}$ is the Congressional Budget Office's measure of full potential employment. Therefore, $U N E M P_{t, 0}^{S P F}-U N E M P_{t, 0}^{*}$ stands for the unemployment gap. I take the values prescribed by these specifications and compare them to the estimated values of the forecast-based models. More specifically, I compare the prescriptions of the Taylor Rule and the ROT rule to the predictions obtained from using only the BOG staff forecasts, SPF forecasts, and the BIC model as given by

$$
\begin{aligned}
\text { Staff }: \hat{r}_{t}^{\text {staff }} & =\gamma_{0}^{\text {staff }}+\gamma_{U N E M P_{t, 0}^{\text {staff }}} U N E M P_{t, 0}^{\text {staff }}+\gamma_{\bar{\pi}_{t, t+3}^{\text {staf }}} \bar{\pi}_{t, t+3}^{\text {staff }} \\
& =1.69-0.44 \times U N E M P_{t, 0}^{\text {staff }}+2.01 \times \bar{\pi}_{t, t+3}^{\text {staf }} \\
\text { SPF }: \hat{r}_{t}^{S P F} & =\gamma_{0}^{S P F}+\gamma_{U N E M P_{t, 0}^{S P F}} U N E M P_{t, 0}^{S P F}+\gamma_{\bar{\pi}_{t, t+3}^{S P F}} \bar{\pi}_{t, t+3}^{S P F} \\
& =-0.09-0.42 \times U N E M P_{t, 0}^{S P F}+2.47 \times \bar{\pi}_{t, t+3}^{S P F} \\
\text { BIC: } \hat{r}_{t}^{\text {BIC }} & =\gamma_{0}^{\text {BIC }}+\gamma_{U N E M P_{t, 0}^{\text {BIC staff }}} U N E M P_{t, 0}^{\text {staff }}+\gamma_{\bar{\pi}_{t, t+3}^{B I C S F}}^{\text {SIC }} \bar{\pi}_{t, t+3}^{S P F} \\
& =-0.04-0.43 \times U N E M P_{t, 0}^{\text {staff }}+2.46 \times \bar{\pi}_{t, t+3}^{S P F}
\end{aligned}
$$

Comparing the forecast-based models to the traditional representations of policy rules determines whether forward-looking models are better at estimating the federal funds target rate. Figure 1, which denotes recessionary periods by gray bars, shows these comparisons. Prior to the 1991 recession, the Taylor Rule prescribed policies that were typically lower than the actual policy rates. Following the recession of 1991, the Taylor rule prescriptions briefly converged with the implemented policy before the target rate picked up. In contrast, the forecast-based estimates remained closer to the actual policy than the Taylor rule prior to the 1991 downturn. As the 1991 recession hit, the prescriptions of the forecast-based models remained higher than the implemented policy. Interestingly, in the mid-1990s, the federal funds rate rebounded and became close to the preferred levels of the forecast-based models while the Taylor Rule continued to prescribe lower rates. As the 2001 recession occurred, the prescriptions of the models converged with the target rate as policy decreased the rates during the downturn. 
FIGURE 1

POLICY ESTIMATES: TAYLOR RULE VS. FORECAST MODELS

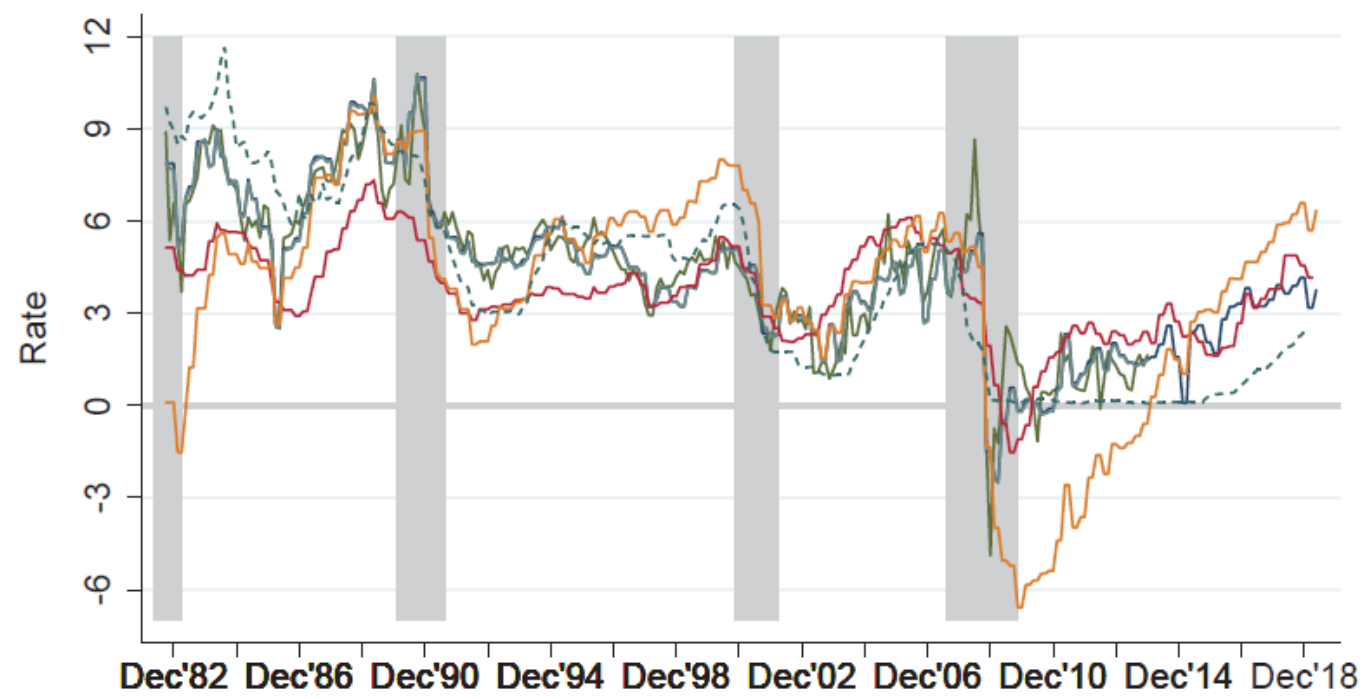

FOMC Meeting Month

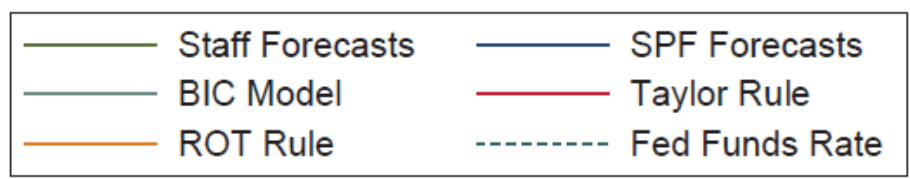

During the Great Moderation period, the Taylor Rule prescribed higher target rates than the rest of the models. In contrast, the forecast-based models remained closer to the implemented policy. As the economy experienced the Great Recession, the Taylor rule, as well as the forecast-based models, suggested target rates below the zero lower bound level. Aside from the ROT rule, the prescriptions of the models rebounded quickly back to a nonnegative interest rate. The ROT level, in contrast, took almost as long as the actual policy itself to get a positive target rate. Still, The ROT rule gives the most volatile policy recommendations.

\section{Time-Varying Policy Determination}

Calibrating a policy rule that describes the determination of monetary policy over a long horizon leads to large prediction errors. Allowing for time-varying parameterization of the coefficient estimates could address this concern and lead to a more accurate characterization of the policy ruling. To incorporate this idea into my analysis, I impose time-varying parameterization of the coefficients by using rolling regressions.

I utilize one-year windows (8 previous meetings) to recalibrate the estimated coefficients of the specifications with forecasts and compare the resulting series to the values given by the Taylor and ROT models. Figure 2 shows the results. I find that recalibrating the parameters leads the estimated values to be closer to the observed policy rates. Notably, the gap between the estimated values and the actual policy is greatly diminished, especially during the Great Moderation.

As the Great Recession hit, both the Taylor rule and ROT model indicated negative interest rates. The forecast models also prescribed negative target rates before following the zero lower bound constraint. The original Taylor rule specification then rebounded shortly after the recession hit to a positive rate while the ROT prescriptions remained negative. The forecast-based models, on the other hand, remained close to the zero level. Because of data-access limits, only the SPF forecasts are available after 2013; however, the values suggested by the SPF model closely map the movements of the federal funds rate, even during the initial liftoff from the zero lower bound constraint. This finding suggests that monetary 
policy does not follow the prescriptions of policy rules using contemporaneous information and reiterates that the policy choice is discretionary, dynamic, and driven by forward-looking economic data.

In addition, the forecast-based values are very close to the actual policy rate even though the rolling regressions do not incorporate the lag values of the fed funds rate. This observation suggests that the choice of monetary policy rests on the economic outlook and not necessarily on previous values. The lag values may simply be reflecting the graduality of changes in economic fundamentals. As a result, it may seem that the Fed is implementing policy smoothing even if it is not actively trying to smooth target rate changes.

I also test how accurate the forecast estimates are after accounting for the actual decisions made by the FOMC. This analysis would then indicate which of the models most closely resembles the policymaking process of the FOMC. To conduct this study, I employ the rolling regression estimation but use the current meeting as the last of the 8 meetings considered in calculating the coefficient estimates.

The revised values are shown in Figure 3. As expected, the fit of the estimates improves. The forecast estimates not only follow the zero lower bound constraint but the SPF-only forecast model - which has more available data - moves together with the observed policy.

To empirically assess whether the actual policy rates are significantly different from the forecast estimates as well as from the prescriptions of the Taylor Rule and ROT, I use a linear regression specification given by

$r_{t}=\alpha+\beta_{\hat{r}^{T Y P E}} \hat{r}_{t}^{T Y P E}+\kappa_{t}$

where TYPE signifies the model specification used. Table 2 gives the results. I find that all of the specifications are statistically significant estimates of the actual policy. However, the explanatory power of both the Taylor Rule as well as the ROT rule are low while the $R^{2}$ of the forecast-based models are very high (equal to 0.99).

My findings suggest that policy determination is forward-looking. The models that incorporate projections are better suited at estimating the actual policy. Hence, the FOMC decides on policy based mainly on how they perceive inflation and employment will change over time.

Moreover, I examine whether the coefficient estimate for the forecast-based policy values is significantly different from 1 to evaluate their accuracy. Referring to table 2 , I find that out of the three forecast-based models, the predictions from the BIC-preferred model is the only one that is not statistically different from the actual policy target rate. This finding further supports the claim that the fed funds target rate is not only based on staff forecasts. Incorporating publicly available forecasts, particularly of inflation, leads to improved estimates of policy determination.

\section{Policy Statements: Content Analysis and Empirical Analysis \\ Dictionary Method}

Because of the widespread attention and influence that policy meeting statements possess, it is also important to understand the economic information they relay to the public. To analyze these documents, I use a semi-automated content analysis approach. I follow the Dictionary method of content analysis presented by Tadle (2020) since it systematically evaluates each statement while accounting for the syntax of the policy document. It then creates a statement index that measures the economic views related to the natural rate of interest. This economic information ultimately guides monetary policy.

Using the Dictionary Method, I examine the statements. I then create a set of keywords that are connected to macroeconomic indicators and are relevant to monetary policy. These keywords are categorized into two sets. The first set is what I call hawkish keywords and these are terms that, when attached to a positive modifier, indicate either higher inflationary pressures or lower unemployment levels, thereby projecting contractionary policy-leaning sentiments. The opposite message is given by the keyword if it is attached to a negative modifier. The second set of keywords, on the other hand, are 
referred to as dovish keywords and they are terms that indicate lower inflationary forecasts or higher unemployment levels when attached to a positive modifier.

To provide some examples of the keyword classification, the keyword 'growth', when preceded by the positive modifier 'solid', signals an expansion. 'Growth', on the other hand, gives a dovish sentiment when it is preceded by the negative modifier 'weak'. Therefore, the keyword 'growth' is categorized as a hawkish keyword. On the other hand, the keyword 'unemployment', if preceded by the positive modifier 'increasing', indicates higher unemployment and is more expansionary policy-leaning. Therefore, 'unemployment' is considered as a dovish keyword.

FIGURE 2

POLICY ESTIMATES: USING ROLLING REGRESSION ESTIMATION (OUT-OF-SAMPLE)

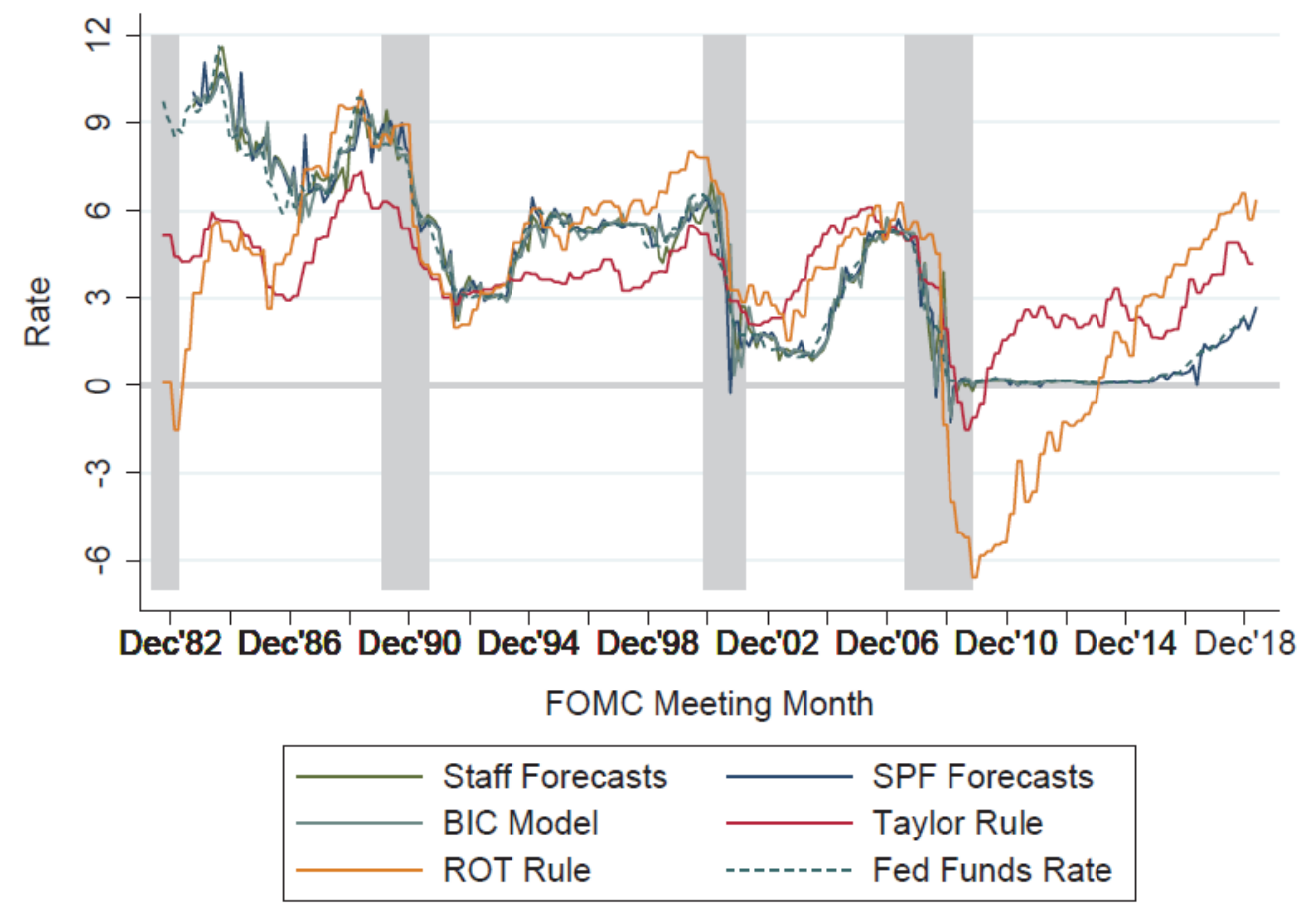


FIGURE 3

POLICY ESTIMATES: USING ROLLING REGRESSION ESTIMATION (IN-SAMPLE)

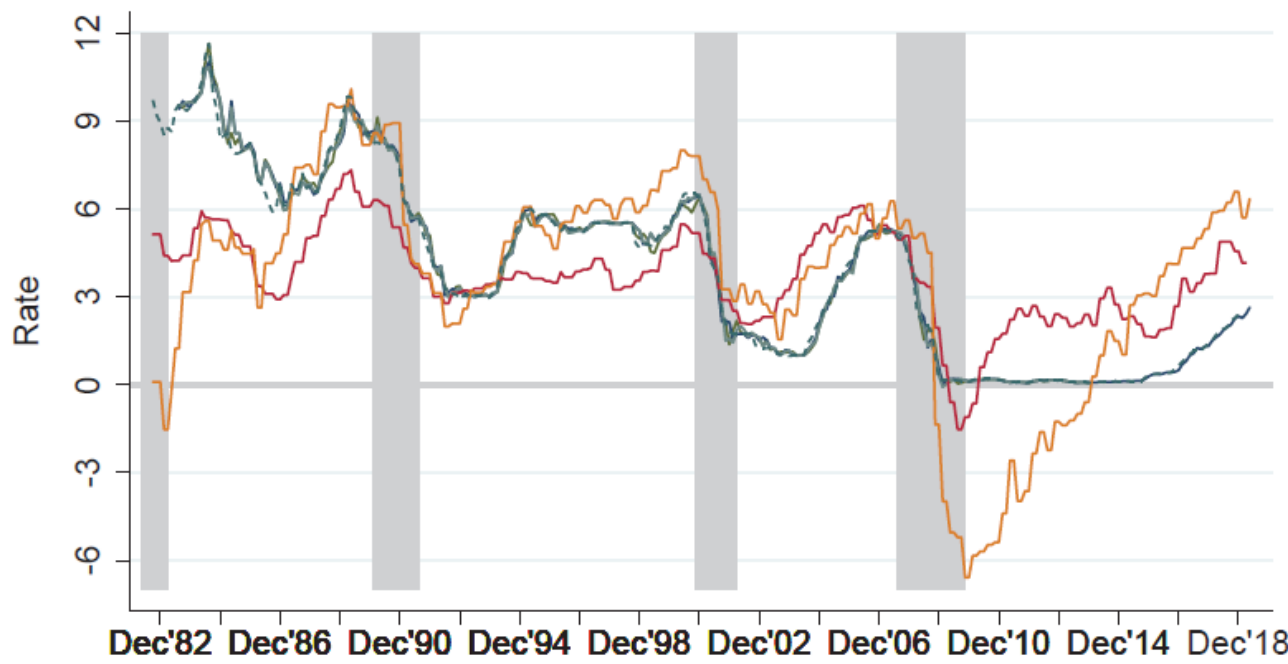

FOMC Meeting Month

\begin{tabular}{|ll|}
\hline Staff Forecasts & \\
BIC Model & SPF Forecasts \\
ROT Rule & Taylor Rule \\
RO------ & Fed Funds Rate \\
\hline
\end{tabular}

TABLE 2

COMPARING ESTIMATES FROM ROLLING REGRESSIONS TO ACTUAL FEDERAL FUNDS RATE

\begin{tabular}{|ccccc|}
\hline Prediction Source & $\boldsymbol{\alpha}$ & $\boldsymbol{\beta}_{\hat{r}_{t}^{\text {TPE }}}$ & $\boldsymbol{R}^{\mathbf{2}}$ & $\boldsymbol{H}_{\mathbf{0}}: \boldsymbol{\beta}_{\hat{\boldsymbol{r}}_{t}^{\text {TYPE }}}=\mathbf{1}$ \\
\cline { 1 - 5 } Taylor Rule & $-1.39^{* * *}$ & $1.45^{* * *}$ & 0.55 & REJECT at $1 \%$ LEVEL \\
& {$[-4.48]$} & {$[18.04]$} & & $(31.68)$ \\
ROT Rule & & & & \\
& $2.52^{* * *}$ & $0.54^{* * *}$ & 0.49 & REJECT at $1 \%$ LEVEL \\
& {$[12.93]$} & {$[19.99]$} & & $(285.04)$ \\
BOG Staff Only & 0.03 & $0.99^{* * *}$ & 0.99 & REJECT at 5\% LEVEL \\
& {$[1.47]$} & {$[153.06]$} & & $(4.24)$ \\
SPF Only & 0.02 & $0.98^{* * *}$ & 0.99 & REJECT at $5 \%$ LEVEL \\
& {$[1.28]$} & {$[140.49]$} & & $(4.72)$ \\
BIC-Preferred Model & 0.03 & $0.99^{* * *}$ & 0.99 & FAIL TO REJECT \\
& {$[1.08]$} & {$[126.35]$} & & $(2.44)$ \\
& & & \\
\hline
\end{tabular}

Note: $* * *$ indicates significance at the $1 \%$ level, ${ }^{* *}$ signifies significance at the $5 \%$ level, and $*$ indicates significance at the $10 \%$ level. The values in brackets are the t-stats while those in parentheses are F-stats. The analyses include all of the FOMC meetings in the period from October 1982 to December 2018. The Regression Specification is $r_{t}=\alpha+\beta_{\hat{r}_{t}^{T Y P E}} \hat{r}_{t}^{T Y P E}+\kappa_{t}$ 
The keywords are used to create a sentence-level examination of the contents of the statements. Sentences without any of these keywords are those that do not include economic discussions and are therefore dropped from the analysis. The rest of the sentences are then scored as follows. Denoting the sentence with keyword type $k$ in document $d$ as sent ${ }_{d, k}$, the sentiment score of the sentence is given based on the number of positive terms, $p$, relative to the number of negative terms, $n$. The sentiment score of $\operatorname{sent}_{d, k}$, score $\left(\operatorname{sent}_{d, k}\right)$, is then calculated using the following metric:

$$
\operatorname{score}\left(\operatorname{sent}_{d, k}\right)=\left\{\begin{array}{cl}
1, & \text { if } k=\text { hawk and } p>n \\
-1, & \text { if } k=\text { hawk and } p<n \\
-1, & \text { if } k=\text { dove and } p>n \\
1, & \text { if } k=\text { dove and } p<n \\
0, & \text { otherwise }
\end{array}\right.
$$

Under these criteria, sentences with a hawkish keyword and have more positive than negative modifiers are given a score of 1, signifying a more contractionary policy-leaning sentence sentiment. On the other hand, sentences with -1 are those that relay more expansionary policy-leaning sentiments. ${ }^{14}$

When calculating the index for a particular document, I consider the increasing length of the statements over time by accounting for the number of sentences with keywords, $n s_{d}$. The calculation for each statement is then given by

$$
\operatorname{index}(d)=100 \times \frac{1}{n s_{d}} \sum \operatorname{score}\left(\operatorname{sent}_{d, k}\right)
$$

The higher the index is, the more contractionary policy-leaning the document is.

TABLE 3

\begin{tabular}{|c|c|c|c|c|}
\hline \multirow[b]{2}{*}{$\begin{array}{c}\text { business } \\
\text { employment } \\
\text { financial } \\
\text { inflation } \\
\text { manufacturing } \\
\text { production } \\
\text { spending }\end{array}$} & \multicolumn{3}{|c|}{ Hawkish Keywords } & \multirow[b]{2}{*}{$\begin{array}{c}\text { economy } \\
\text { expansion } \\
\text { indicators } \\
\text { labor } \\
\text { prices } \\
\text { slack } \\
\text { wages }\end{array}$} \\
\hline & $\begin{array}{l}\text { businesses } \\
\text { energy } \\
\text { growth } \\
\text { inflationary } \\
\text { outlook } \\
\text { recovery } \\
\text { target }\end{array}$ & $\begin{array}{l}\text { demand } \\
\text { equities } \\
\text { housing } \\
\text { investment } \\
\text { output } \\
\text { resource } \\
\text { toll }\end{array}$ & $\begin{array}{c}\text { economic } \\
\text { equity } \\
\text { income } \\
\text { investments } \\
\text { price } \\
\text { securities } \\
\text { wage }\end{array}$ & \\
\hline \multicolumn{5}{|c|}{ Dovish Keywords } \\
\hline & $\begin{array}{l}\text { accommodation } \\
\text { recession }\end{array}$ & $\begin{array}{c}\text { devastation } \\
\text { unemployment }\end{array}$ & downturn & \\
\hline
\end{tabular}
KEYWORDS

The keywords are listed by classification in Table 3 while the modifiers are listed in Appendix A2. As can be seen from Table 3, there are more hawkish than dovish keywords. This contrast arises from the wording that the statements have in the time period analyzed. Given that the sentence scoring is also based on the relative number of modifiers and not just on the keyword, the results are not impacted by the difference between the number of hawkish keywords and the number of dovish keywords.

\section{Applying the Dictionary Method on the Monetary Policy Statements}

With the dictionary method, sentiment scores can range from -100 to +100 . The sentiment scores are calculated such that larger scores reflect a higher concentration of discussions that are more 
contractionary monetary policy leaning. The lower sentiment scores, on the other hand, convey a larger concentration of discussions that are expansionary monetary policy leaning.

I calculate a series of statement sentiment scores for the meetings from May 18, 1999, when the statements are first released similar to their current form to December 18, 2013, the data corresponding to the most current data for staff forecasts. Figure 4 represents the resulting series of sentiment scores. Noting the areas covered by the gray bars as recessionary periods, I find that during economic boom periods, the sentiments of the information in the statements were more hawkish. As downturns approached, the sentiment scores declined. During the 2001 recession, a downward sentiment trend occurred as the recession approached. In contrast, earlier in the Great Recession, the downward trend of the statement sentiments seem to have reversed a bit before dropping further once the depth of the downturn is realized. ${ }^{15}$

\section{Empirical Specification and Results: Sentiment Index}

The economic outlook conveyed by the statements receives much attention since they relay information relevant to the monetary policy decision-making process. This set of information may incorporate discussions included in staff forecasts. They may also highlight relevant economic data that is more consistent with publicly available information.

To more effectively guide policy expectations, the FOMC may format the document discussions to portray the combination of economic information used when deciding the monetary policy. In light of this possibility, I examine the type of forecasts that could be influencing statement discussions. I evaluate whether the forecasts from the staff or SPF forecasts are more likely to explain the sentiments of the documents.

Table 4 presents the results. In the first column, the variables considered are the four-quarter averages for inflation and the nowcasts for unemployment from the two forecast types. With this set of variables, the BIC model selection prefers to simply use the BOG staff four-quarter inflation average as the regressor. The resulting coefficient estimate is positive and significant at the $1 \%$ level.

In the second column, I also include the nowcasts of real GDP growth as well as the unemployment gap as possible independent variables. The results indicate that the specification with the staff fourquarter inflation average as well as the staff nowcast for real GDP growth has the lowest likelihood value. Therefore, the BIC prefers this specification the most. The corresponding coefficient estimates for these regressors are positive and also highly significant. 
FIGURE 4

STATEMENT SENTIMENT SCORES

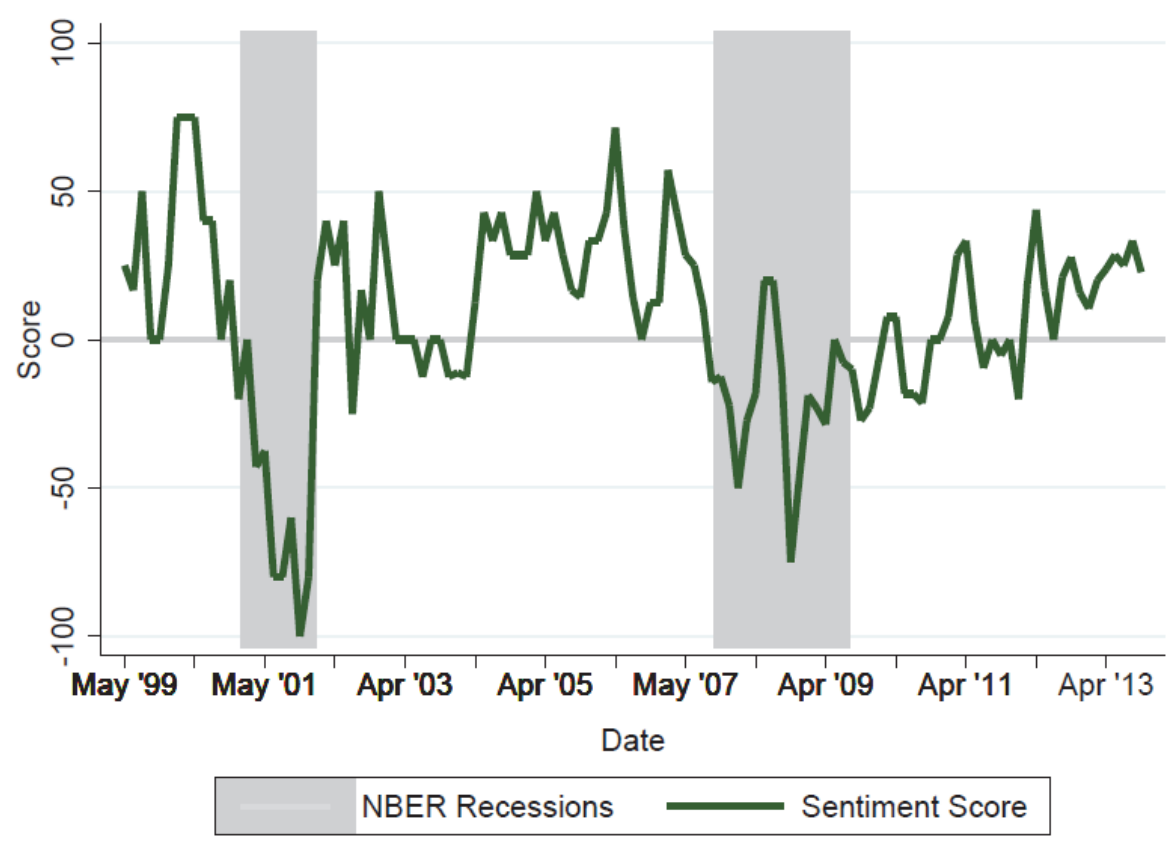

In the third column, I add the lag value of the sentiment score to the list of considered variables to account for the persistence in the wording of the statements. I find that the specification preferred by the BIC replaces the staff four-quarter inflation forecast with the lag value of the sentiment score. The coefficient for the lag value of the sentiment score is positive and highly statistically significant.

These results suggest that the overall sentiments of the statements represent information that is more consistent with the staff forecasts than the SPF forecasts. Therefore, the discussions on economic information found in post-meeting statements reflect those that have not been previously distributed to the public. ${ }^{16}$ With this additional clarity on information considered for monetary policy decisions, the financial markets react based on adjustments in the path that monetary policy and economic indicators are expected to take in the future.

\section{Robustness and Extensions}

Adding the Projected Real GDP Growth and Unemployment Gap

Considering the forecasts for unemployment and inflation, I find that the economic information used in monetary policymaking is consistent with a combination of unemployment projections from the BOG staff and inflation forecasts from the SPF. However, projections of other economic variables may also play an important role in determining policy. Therefore, incorporating them in the analysis will provide more understanding of the overall economic outlook that the FOMC considers when forming policy.

To evaluate a wider set of forecast variables, I include the nowcasts of the real GDP growth as well as the unemployment gap, the deviation of unemployment forecasts from the estimated fullpotential unemployment level. ${ }^{17,18}$ The real GDP growth is used in alternative versions of the Taylor rule, such as the specification used in Coibion and Gorodnichenko (2012). On the other hand, the estimated unemployment gap is a measure of the deviation of unemployment forecasts from the full-potential unemployment and provides a scale of how far employment levels are from what could be perceived as their equilibrium level. 
TABLE 4

REGRESSION RESULTS: FORECASTS REFLECTED IN THE STATEMENT SENTIMENTS

\begin{tabular}{|c|c|c|c|}
\hline Independent Variables & Original Specification & W/ RGDPGR \& UGAP & W/ RGDPGR, UGAP, \& $s_{t-1}$ \\
\hline & {$[1]$} & {$[2]$} & {$[3]$} \\
\hline$s_{t-1}$ & & & $\begin{array}{c}0.61 * * * \\
(0.09)\end{array}$ \\
\hline $\bar{\pi}_{t, t+3}^{\text {Staff }}$ & $\begin{array}{c}14.75 * * * \\
(3.24)\end{array}$ & $\begin{array}{c}8.61 * * * \\
(2.99)\end{array}$ & \\
\hline$R G D P G R_{t, 0}^{\text {Staff }}$ & & $\begin{array}{c}7.93 * * * \\
(1.78)\end{array}$ & $\begin{array}{c}3.52 * * * \\
(1.32)\end{array}$ \\
\hline Constant & $\begin{array}{r}-21 * * * \\
(6.53)\end{array}$ & $\begin{array}{c}-26.55^{* * *} \\
(7.96)\end{array}$ & $\begin{array}{c}-4.9 \\
(3.55)\end{array}$ \\
\hline$R^{2}$ & 0.12 & 0.34 & 0.56 \\
\hline $\mathrm{N}$ & 118 & 118 & 117 \\
\hline ROOT MSE & 30.64 & 26.73 & 21.83 \\
\hline f-stat p-value & 0 & 0 & 0 \\
\hline Mean VIF & 1 & 1.1 & 1.42 \\
\hline
\end{tabular}

Table 5 shows the results for the specifications recommended by the BIC model criterion. The first column demonstrates the results of the original specification. The second column incorporates the real GDP growth nowcasts and lag fed funds rate as possible additions to the model specification. Considering the expanded set of forecasts, the BIC suggests adding the lag fed funds rate and the staff nowcast for real GDP growth. Both of these have positive and highly statistically significant coefficient estimates. The SPF nowcast for unemployment, however, is preferred to its staff counterpart in this forecast variable selection set and is negative and statistically significant. In addition, the coefficient for the four-quarter average SPF forecasts for inflation is positive and significant at the $1 \%$ level.

The third column considers the lag level of the federal funds rate as well as the nowcast of real GDP growth, unemployment, and the unemployment gap. I find the results to be very similar to those in the second column. The only difference is that the unemployment gap using the staff nowcast replaces the staff nowcast for unemployment.

Hence, these results further support the notion that the information on inflation used by the FOMC members is more consistent with publicly available information than those from the staff. The findings also point out that publicly available forecasts on real GDP growth are more in line with information that affects policy decisions than their BOG staff forecast counterparts.

\section{Incorporating all Variables for Predictions of the Policy Rate}

In the earlier assessment, information criteria - particularly the BIC - were used to select the model that best fits the monetary policy rate decisions and statements while accounting for the number of explanatory variables. The potential problem with this selection method, however, is that the resulting model may not be the best predictor of the policy rate and statement sentiments. To account for this possibility, I incorporated all of the macroeconomic indicators I considered earlier - inflation, real GDP growth, unemployment, and unemployment gap - to examine whether the root mean squared error of the resulting predictions are lower. 
TABLE 5

REGRESSION RESULTS: INCORPORATING GDP GROWTH AND UNEMPLOYMENT

\begin{tabular}{|c|c|c|c|}
\hline Independent Variables & Original Specification & W/ RGDPGR \& $\mathbf{r}_{\mathrm{t}-1}$ & W/ UGAP, RGDPGR, \& $\mathbf{r}_{\mathrm{t}-1}$ \\
\hline & {$[1]$} & {$[2]$} & {$[3]$} \\
\hline$r_{t-1}$ & & $\begin{array}{c}0.94 * * * \\
(0.02)\end{array}$ & $\begin{array}{c}0.94^{* * *} \\
(0.02)\end{array}$ \\
\hline$U N E M P_{t, 0}^{\text {Staff }}$ & $\begin{array}{c}-0.43 * * * \\
(0.06)\end{array}$ & & \\
\hline$U N E M P_{t, 0}^{S P F}$ & & $\begin{array}{c}-0.03 * * \\
(0.01)\end{array}$ & \\
\hline$R G D P G R_{t, 0}^{\text {Staff }}$ & & $\begin{array}{c}0.08^{* * * *} \\
(0.01)\end{array}$ & $\begin{array}{c}0.08^{* * * *} \\
(0.01)\end{array}$ \\
\hline $\bar{\pi}_{t, t+3}^{S P F}$ & $\begin{array}{c}2.46^{* * * *} \\
(0.10)\end{array}$ & $\begin{array}{c}0.14 * * * \\
(0.04)\end{array}$ & $\begin{array}{c}0.13^{* * *} \\
(0.04)\end{array}$ \\
\hline$U G A P_{t, 0}^{S P F}$ & & & $\begin{array}{c}-0.04 * * \\
(0.01)\end{array}$ \\
\hline Constant & $\begin{array}{l}-0.04 \\
(0.51)\end{array}$ & $\begin{array}{l}-0.16 \\
(0.1)\end{array}$ & $\begin{array}{c}-0.31 * * * \\
(0.09)\end{array}$ \\
\hline$R^{2}$ & 0.76 & 0.99 & 0.99 \\
\hline $\mathrm{N}$ & 251 & 250 & 250 \\
\hline ROOT MSE & 1.47 & 0.28 & 0.28 \\
\hline f-stat p-value & 0 & 0 & 0 \\
\hline Mean VIF & 1 & 2.45 & 2.54 \\
\hline
\end{tabular}

Note: $* * *$ indicates significance at the $1 \%$ level, ${ }^{* *}$ signifies significance at the $5 \%$ level, and $*$ indicates significance at the $10 \%$ level. The values in parentheses are robust standard errors. The analyses include all of the FOMC meetings in the period from October 1982 to October 2008. The dependent variable is the average effective federal funds rate for the month during which the meeting was held. Regression specifications are based on those recommended by BIC model selection criterion.

The results of this exercise indicate that adding all of the variables does not significantly decrease the root mean squared error (remains at 0.28). ${ }^{19}$ The mean Variance Inflation Factor, on the other hand, rose from 2.54 to 70.26 . Therefore, the predictions from incorporating all of the macroeconomic forecasts seem to suffer from multicollinearity while not necessarily improving the fit of the model.

In addition, I find that the statement sentiments are primarily explained by a combination of staff forecasts and policy decisions. However, the fit does not improve significantly while the mean VIF rose tremendously. The appropriate model then for explaining the statement sentiments seems to be the one that does not arbitrarily include all macroeconomic forecasts.

\section{CONCLUSION}

Monetary policy is best estimated using projections of economic indicators. Although the economic forecasts that the BOG staff prepares are superior to most projections, the FOMC does not solely depend on such information to decide the appropriate policy to implement. Analyzing the influence of publicly available information, I find that the FOMC considers inflation projections that are more similar to those that are publicly available than to those compiled by the BOG staff. Using this information, the FOMC avoids large policy surprises since the policy target is more consistent with the expected rate.

The FOMC also recognizes the need to convey its privately-held information to further guide policy expectations. The committee infuses such information in their post-meeting statements and other policy documents and press briefings. In doing so, the committee members can more effectively use 
transparency and communication to impact financial markets and lead relevant economic indicators to their targeted levels.

\section{ENDNOTES}

1. The U.S. Congress considered a bill back in 2014 that would have forced the Fed to follow a variant of the Taylor Rule when determining the Federal Funds Rate. See Walsh (2015) for further discussions.

2. The FOMC members, themselves, also prepare their own forecasts of relevant macroeconomic variables, such as unemployment and inflation, and such forecasts span several years ahead. However, as Romer and Romer (2008) argue, the FOMC member forecasts, which are reported twice a year in the semiannual Monetary Policy Reports, are still not as reliable as the staff projections even though the FOMC members can refer to these forecasts while making their own.

3. CPI inflation is the preferred inflation measure in this analysis given that CPI served as the Fed's main measure of the price level from the 1980's up to the very early 2000's. Furthermore, as Romer and Romer (2000), Kahn (2010), and El-Shagi et al. (2014) demonstrate, the choice of the measure for inflation does not take away from the main results.

4. Using the mean SPF forecasts does not qualitatively affect the results.

5. There is a potential issue regarding the use of the SPF forecasts on real GNP/GDP growth. Before the first quarter of 1992, this variable was measured in terms of the real GNP annualized growth. However, it was later changed to real GDP growth. Given that this is the same change that occurred in the staff forecasts, I am assuming that the change does not alter the results.

6. Restricting the analysis for the fed funds rate to 2008 when the rates were constrained by the zero lower bound yield similar results.

7. In my results, I report t-statistics based on the calculated Newey West standard errors. These account for potential heteroskedasticity and autocorrelation of forecast errors. In my estimation, I consider a maximum of four lags for the autoregressive structure of the errors.

8. Taking the quarterly forecast of inflation for up to three quarters ahead gives similar results. However, using this specification increases the likelihood of multicollinearity.

9. Considering other horizons of unemployment give similar results.

10. I also examine the model specifications recommended by the Akaike Information Criterion (AIC). However, the models that AIC suggests are very similar to those suggested by BIC but are more likely to suffer from multicollinearity.

11. The VIF of the regression models are acceptable since they are less than 10, the threshold tolerance value suggested by Neter et al. (1996).

12. To account for generated regressors, I also calculated the bootstrapped standard errors using 10,000 replications. The results remain robust under this examination.

13. I use the four-quarter average SPF forecast for inflation as well as the staff nowcast for unemployment to be consistent with the BIC-only model specification.

14. I also consider the impact of negation terms by reversing the effect of a modifier if it is immediately preceded by a negation term. The negation terms I consider are 'fail', 'less', 'never', 'no', 'not', 'opposed', and 'unlikely'.

15. Stekler and Symington (2016) confirm a similar pattern in the FOMC minutes. Examining the qualitative information in the meeting minutes, they find that the FOMC overestimated the impact of its initial policy response to the onset of the Great Recession. The FOMC members were also concerned about the inflationary pressures faced by the U.S. economy and this contributed to the reversal of the document sentiments in these early stages of the downturn.

16. Statement discussions may not fully address the uncertainty that the public face regarding both policy and economic outlook. In order for the FOMC to decrease some of the uncertainty, it has increased the length of the documents and in 2011, has begun to include a summary of economic projections in their post-meeting releases.

17. Including additional horizons for these forecasts does not qualitatively alter the results.

18. I also include the lag value of the fed funds rate from the previous meeting in order to show the robustness of the findings. Omitting it lowers the $R^{2}$ (0.76 and 0.84 for columns [2] and [3], respectively) but does not qualitatively affect the results.

19. Results are available upon request. 


\section{REFERENCES}

Bernanke, B. S. et al. (2007). Inflation Expectations and Inflation Forecasting. In speech at the Monetary Economics Workshop of the National Bureau of Economic Research Summer Institute, Cambridge, Massachusetts.

Branch, W. A. (2014). Nowcasting and the Taylor Rule. Journal of Money, Credit and Banking, 46(5), $1035-1055$.

Coibion, O. and Gorodnichenko, Y. (2012). Why are Target Interest Rate Changes so Persistent? American Economic Journal: Macroeconomics, 4(4), 126-162.

El-Shagi, M., Giesen, S., \& Jung, A. (2014). Does the Federal Reserve Staff Still Beat Private Forecasters?

Elias, E., Irvin, H., \& Jorda, O. (2014). Monetary policy when the spyglass is smudged. FRBSF Economic Letter, 2014, 35.

Furnival, G. M., \& Wilson, R. W. (2000). Regressions by Leaps and Bounds. Technometrics, 42(1):6979.

Gavin, W. T., \& Mandal, R. J. (2003). Evaluating FOMC Forecasts. International Journal of Forecasting, 19(4), 655-667.

Kahn, G. A. (2010). Taylor Rule Deviations and Financial Imbalances. Economic Review-Federal Reserve Bank of Kansas City, 95(2), 63.

Neter, J., Kutner, M. H., Nachtsheim, C. J., \& Wasserman, W. (1996). Applied Linear Statistical Models, volume 4. Irwin Chicago.

Ni, X. S., \& Huo, X. (2006). Regressions by Enhanced Leaps-and-Bounds via Additional Optimality Tests (LBOT). Technical report, Citeseer.

Nikolsko-Rzhevskyy, A., Papell, D. H., \& Prodan, R. (2014). Deviations from Rules-based Policy and their Effects. Journal of Economic Dynamics and Control, 49, 4-17.

Orphanides, A., \& Wieland, V. (2008). Economic Projections and Rules-of-thumb for Monetary Policy.

Romer, C. D., \& Romer, D. H. (2000). Federal Reserve Information and the Behavior of Interest Rates (Digest Summary). American Economic Review, 90(3), 429-457.

Romer, C. D., \& Romer, D. H. (2008). The FOMC versus the Staff: Where can Monetary Policymakers add Value? Technical report, National Bureau of Economic Research.

Stekler, H., \& Symington, H. (2016). Evaluating Qualitative Forecasts: The FOMC Minutes, 2006-2010. International Journal of Forecasting, 32(2), 559-570.

Tadle, R. (2020). FOMC Sentiment Extraction and Its Transmission to Financial Markets.

Taylor, J. B. (1993). Discretion versus Policy Rules in Practice. In Carnegie-Rochester conference series on public policy, 39, 195-214. Elsevier.

Taylor, J. B. (2012). Monetary Policy Rules Work and Discretion Doesn't: A Tale of Two Eras. Journal of Money, Credit and Banking, 44(6), 1017-1032.

Taylor, J. B., \& Bean, C. (2010). Commentary: Monetary Policy after the Fall. In Jackson Hole Conference.

Walsh, C. E. (2015). Goals and Rules in Central Bank Design.

Walsh, C. E. (2001). The Science (and Art) of Monetary Policy. FRBSF Economic Letter. 


\section{APPENDIX}

\section{Rationality Tests}

To evaluate the accuracy of forecasts on economic indicators, I compare them to the realized values. I also examine if they are significantly different from the observed data. Table A1 provides BOG staff forecasts for unemployment. I observe that for all forecast horizons, the coefficient estimate for the forecast is positive and statistically significant at the $1 \%$ level. These imply that the forecasts for different horizons are positively correlated with the actual values. Interestingly, the coefficient estimates are close to 1, thereby supporting the accuracy of these forecasts. I also observe the results of the tests evaluating whether the coefficient estimates are significantly different from 1 . They indicate that my evaluation fails to find a statistical difference between the forecasts and realized values. This set of results further suggests that staff forecasts are able to accurately project the actual values of unemployment.

TABLE A1

RATIONALITY TESTS FOR BOG STAFF UNEMPLOYMENT FORECASTS

\begin{tabular}{|c|c|c|c|c|}
\hline $\begin{array}{l}\text { Forecast Horizon q } \\
\quad \text { (in quarters) }\end{array}$ & $\alpha$ & $\beta_{U N E M P}^{\text {Staff }}$ & Max Lags & $H_{0}: \beta_{U N E M P}^{\text {Staff }}=1$ \\
\hline Nowcast & $\begin{array}{c}0.12 \\
{[1.34]}\end{array}$ & $\begin{array}{l}0.98^{* * *} \\
{[64.45]}\end{array}$ & 4 & $\begin{array}{c}\text { FAIL TO REJECT } \\
(2.6)\end{array}$ \\
\hline 1 Quarter Ahead & $\begin{array}{c}0.1 \\
{[0.99]}\end{array}$ & $\begin{array}{l}0.97 * * * \\
{[57.56]}\end{array}$ & 4 & $\begin{array}{l}\text { FAIL TO REJECT } \\
(2.59)\end{array}$ \\
\hline 2 Quarters Ahead & $\begin{array}{c}0.1 \\
{[0.67]}\end{array}$ & $\begin{array}{l}0.97 * * * \\
{[40.05]}\end{array}$ & 4 & $\begin{array}{c}\text { FAIL TO REJECT } \\
(1.27)\end{array}$ \\
\hline 3 Quarters Ahead & $\begin{array}{c}0.07 \\
{[0.35]}\end{array}$ & $\begin{array}{l}0.98^{* * *} \\
{[28.09]}\end{array}$ & 4 & $\begin{array}{c}\text { FAIL TO REJECT } \\
(0.48)\end{array}$ \\
\hline 4 Quarters Ahead & $\begin{array}{c}0.02 \\
{[0.07]}\end{array}$ & $\begin{array}{l}0.99 * * * \\
{[21.75]}\end{array}$ & 4 & $\begin{array}{c}\text { FAIL TO REJECT } \\
(0.09)\end{array}$ \\
\hline
\end{tabular}

A similar pattern is observed for the SPF forecasts in table A2. I find that the SPF forecasts are positive and strongly correlated with the realized values. These coefficient estimates have values that are approximately equal to 1 . The additional hypothesis tests confirm that the SPF forecasts also perform well in estimating unemployment in different horizons. 
TABLE A2

\section{RATIONALITY TESTS FOR SPF UNEMPLOYMENT FORECASTS}

\begin{tabular}{|c|c|c|c|c|}
\hline $\begin{array}{l}\text { Forecast Horizon q } \\
\quad \text { (in quarters) }\end{array}$ & $\alpha$ & $\beta_{U N E M P}^{S P F}$ & Max Lag & $H_{0}: \beta_{U N E M P}^{S P F}=1$ \\
\hline Nowcast & $\begin{array}{r}0.04 \\
{[0.5]}\end{array}$ & $\begin{array}{l}0.99 * * * \\
{[69.60]}\end{array}$ & 4 & $\begin{array}{c}\text { FAIL TO REJECT } \\
(0.94)\end{array}$ \\
\hline 1 Quarter Ahead & $\begin{array}{c}0.01 \\
{[0.16]}\end{array}$ & $\begin{array}{l}0.99 * * * \\
{[61.63]}\end{array}$ & 4 & $\begin{array}{c}\text { FAIL TO REJECT } \\
(0.66)\end{array}$ \\
\hline 2 Quarters Ahead & $\begin{array}{c}-0.03 \\
{[-0.25]}\end{array}$ & $\begin{array}{l}0.99 * * * \\
{[49.01]}\end{array}$ & 4 & $\begin{array}{c}\text { FAIL TO REJECT } \\
(0.08)\end{array}$ \\
\hline 3 Quarters Ahead & $\begin{array}{c}-0.01 \\
{[-0.03]}\end{array}$ & $\begin{array}{l}0.99 * * * \\
{[37.37]}\end{array}$ & 4 & $\begin{array}{c}\text { FAIL TO REJECT } \\
(0.08)\end{array}$ \\
\hline 4 Quarters Ahead & $\begin{array}{c}-0.05 \\
{[-0.26]}\end{array}$ & $\begin{array}{l}1.01 * * * \\
{[29.17]}\end{array}$ & 4 & $\begin{array}{c}\text { FAIL TO REJECT } \\
(0.02)\end{array}$ \\
\hline
\end{tabular}

TABLE A3

RATIONALITY TESTS FOR BOG STAFF CPI INFLATION FORECASTS

\begin{tabular}{|c|c|c|c|c|}
\hline $\begin{array}{l}\text { Forecast Horizon q } \\
\quad \text { (in quarters) }\end{array}$ & $\alpha$ & $\beta_{\text {INFLA }}^{\text {Staff }}$ & Max Lag & $H_{0}: \beta_{\text {INFLA }}^{\text {Staff }}=1$ \\
\hline Nowcast & $\begin{array}{c}0.21 \\
{[0.9]}\end{array}$ & $\begin{array}{r}0.9 * * * \\
{[11.87]}\end{array}$ & 4 & $\begin{array}{l}\text { FAIL TO REJECT } \\
\qquad(1.65)\end{array}$ \\
\hline 1 Quarter Ahead & $\begin{array}{c}0.7 \\
{[1.34]}\end{array}$ & $\begin{array}{c}0.75 * * * \\
{[4.78]}\end{array}$ & 4 & $\begin{array}{l}\text { FAIL TO REJECT } \\
\qquad(2.58)\end{array}$ \\
\hline 2 Quarters Ahead & $\begin{array}{c}1.53 * * * \\
{[3.84]}\end{array}$ & $\begin{array}{c}0.46 * * * \\
{[3.65]}\end{array}$ & 4 & $\begin{array}{c}\text { REJECT at } 1 \% \text { LEVEL } \\
(18.46)\end{array}$ \\
\hline 3 Quarters Ahead & $\begin{array}{c}1.53 * * * \\
{[3.88]}\end{array}$ & $\begin{array}{c}0.46^{* * *} \\
{[3.7]}\end{array}$ & 4 & $\begin{array}{c}\text { REJECT at } 1 \% \text { LEVEL } \\
(18.31)\end{array}$ \\
\hline 4 Quarters Ahead & $\begin{array}{c}1.44 * * * \\
{[3.37]}\end{array}$ & $\begin{array}{l}0.5^{* * * *} \\
{[3.84]}\end{array}$ & 4 & $\begin{array}{c}\text { REJECT at } 1 \% \text { LEVEL } \\
(15.27)\end{array}$ \\
\hline
\end{tabular}

As for CPI inflation forecasts, tables A3 and A4 provide the results for BOG staff and SPF forecasts, respectively. I do not find any significant differences between the actual values and staff nowcasts and between the observed values and the SPF nowcasts. However, both types perform worse in forecasting farther ahead horizons of headline inflation.

The results for forecasts on real GDP growth, given by tables A5 and A6, also show similar patterns as the forecasts for unemployment. The main difference is that the SPF projections have coefficients larger than one. This finding indicates the SPF has a slight tendency, on average, to underpredict the magnitude of real GDP growth compared to the BOG staff. Still, the SPF forecasts are not statistically different from the actual values, thereby indicating that these forecast real GDP growth well. 
TABLE A4

RATIONALITY TESTS FOR SPF CPI INFLATION FORECASTS

\begin{tabular}{|c|c|c|c|c|}
\hline $\begin{array}{l}\text { Forecast Horizon q } \\
\quad \text { (in quarters) }\end{array}$ & $\alpha$ & $\beta_{I N F L A}^{S P F}$ & Max Lag & $H_{0}: \beta_{I N F L A}^{S P F}=1$ \\
\hline Nowcast & $\begin{array}{l}-0.58^{*} \\
{[-1.78]}\end{array}$ & $\begin{array}{l}1.18 * * * \\
{[10.62]}\end{array}$ & 4 & $\begin{array}{c}\text { FAIL TO REJECT } \\
(2.65)\end{array}$ \\
\hline 1 Quarter Ahead & $\begin{array}{c}0.12 \\
{[0.22]}\end{array}$ & $\begin{array}{c}0.89 * * * \\
{[5.12]}\end{array}$ & 4 & $\begin{array}{c}\text { FAIL TO REJECT } \\
(0.38)\end{array}$ \\
\hline 2 Quarters Ahead & $\begin{array}{c}0.6 \\
{[1.15]}\end{array}$ & $\begin{array}{c}0.71 * * * \\
{[4.26]}\end{array}$ & 4 & $\begin{array}{c}\text { REJECT at } 10 \% \text { LEVEL } \\
(3.1)\end{array}$ \\
\hline 3 Quarters Ahead & $\begin{array}{c}0.58 \\
{[1.12]}\end{array}$ & $\begin{array}{l}0.7 * * * \\
{[4.42]}\end{array}$ & 4 & $\begin{array}{c}\text { REJECT at } 10 \% \text { LEVEL } \\
(3.59)\end{array}$ \\
\hline 4 Quarters Ahead & $\begin{array}{c}0.57 \\
{[1.13]}\end{array}$ & $\begin{array}{c}0.69 * * * \\
{[4.61]}\end{array}$ & 4 & $\begin{array}{c}\text { REJECT at } 5 \% \text { LEVEL } \\
(4.33)\end{array}$ \\
\hline
\end{tabular}

TABLE A5

RATIONALITY TESTS FOR BOG STAFF REAL GDP GROWTH

\begin{tabular}{|c|c|c|c|c|}
\hline $\begin{array}{c}\text { Forecast Horizon q } \\
\text { (in quarters) }\end{array}$ & $\alpha$ & $\beta_{R G D P G R}^{\text {Staff }}$ & Max Lag & $H_{0}: \beta_{R G D P G R}^{\text {Staff }}=1$ \\
\hline Nowcast & $\begin{array}{l}0.55^{*} \\
{[1.83]}\end{array}$ & $\begin{array}{l}0.97 * * * \\
{[10.67]}\end{array}$ & 4 & $\begin{array}{c}\text { FAIL TO REJECT } \\
(0.12)\end{array}$ \\
\hline 1 Quarter Ahead & $\begin{array}{c}0.32 \\
{[0.59]}\end{array}$ & $\begin{array}{c}0.98 * * * \\
{[5.36]}\end{array}$ & 4 & $\begin{array}{c}\text { FAIL TO REJECT } \\
(0.01)\end{array}$ \\
\hline 2 Quarters Ahead & $\begin{array}{c}0.55 \\
{[0.59]}\end{array}$ & $\begin{array}{c}0.84 * * * \\
{[2.76]}\end{array}$ & 4 & $\begin{array}{c}\text { FAIL TO REJECT } \\
(0.28)\end{array}$ \\
\hline 3 Quarters Ahead & $\begin{array}{c}1.04 \\
{[0.99]}\end{array}$ & $\begin{array}{l}0.65^{*} \\
{[1.96]}\end{array}$ & 4 & $\begin{array}{c}\text { FAIL TO REJECT } \\
(1.09)\end{array}$ \\
\hline 4 Quarters Ahead & $\begin{array}{c}1.24 \\
{[1.31]}\end{array}$ & $\begin{array}{l}0.57^{*} \\
{[1.84]}\end{array}$ & 4 & $\begin{array}{c}\text { FAIL TO REJECT } \\
(1.92)\end{array}$ \\
\hline
\end{tabular}

Note: $* * *$ indicates significance at the $1 \%$ level, ${ }^{* *}$ signifies significance at the $5 \%$ level, and ${ }^{*}$ indicates significance at the $10 \%$ level. The values in brackets are the t-stats computed using Newey-West Standard Errors. Those in parentheses are f-stat values.The analyses include the last FOMC meeting of each quarter in the period from October 1982 to December 2013. The Regression Specification is $R G D P G R_{t, q}=\alpha+\beta_{R G D P G R}^{\text {Staff }} R G D P G R_{t, q}^{\text {Staff }}+\varepsilon_{t}$ 
TABLE A6

RATIONALITY TESTS FOR SPF REAL GDP GROWTH

\begin{tabular}{|c|c|c|c|c|}
\hline $\begin{array}{l}\text { Forecast Horizon q } \\
\quad \text { (in quarters) }\end{array}$ & $\alpha$ & $\beta_{R G D P G R}^{S P F}$ & Max Lag & $H_{0}: \beta_{R G D P G R}^{S P F}=1$ \\
\hline Nowcast & $\begin{array}{c}0.12 \\
{[0.35]}\end{array}$ & $\begin{array}{c}1.13 * * * \\
{[8.98]}\end{array}$ & 4 & $\begin{array}{c}\text { FAIL TO REJECT } \\
(1.01)\end{array}$ \\
\hline 1 Quarter Ahead & $\begin{array}{c}-0.76 \\
{[-1.14]}\end{array}$ & $\begin{array}{c}1.38 * * * \\
{[5.83]}\end{array}$ & 4 & $\begin{array}{c}\text { FAIL TO REJECT } \\
(2.55)\end{array}$ \\
\hline 2 Quarters Ahead & $\begin{array}{c}-1.17 \\
{[-1.07]}\end{array}$ & $\begin{array}{c}1.48 * * * \\
{[3.94]}\end{array}$ & 4 & $\begin{array}{c}\text { FAIL TO REJECT } \\
(1.62)\end{array}$ \\
\hline 3 Quarters Ahead & $\begin{array}{l}-0.67 \\
{[-0.5]}\end{array}$ & $\begin{array}{c}1.24 * * * \\
{[2.79]}\end{array}$ & 4 & $\begin{array}{c}\text { FAIL TO REJECT } \\
(0.29)\end{array}$ \\
\hline 4 Quarters Ahead & $\begin{array}{c}0.98 \\
{[0.75]}\end{array}$ & $\begin{array}{c}0.65 \\
{[1.45]}\end{array}$ & 4 & $\begin{array}{c}\text { FAIL TO REJECT } \\
(0.62)\end{array}$ \\
\hline
\end{tabular}

\section{Modifiers}

The list of modifiers are given by the following tables.

TABLE A7

POSITIVE MODIFIERS

\begin{tabular}{ccccc}
\hline \hline abating & accelerated & add & advance & advanced \\
augmented & balanced & better & bolsters & boom \\
booming & boost & boosted & eased & elevated \\
elevating & expand & expanding & expansionary & extend \\
extended & fast & faster & firmer & gains \\
growing & heightened & high & higher & improved \\
improvement & improving & increase & increased & increases \\
increasing & more & raise & rapid & rebounded \\
recovering & rise & risen & rising & robust \\
rose & significant & solid & sooner & spike \\
spikes & spiking & stable & strength & strengthen \\
strengthened & strengthens & strong & stronger & stronger-than-expected \\
supportive & up & upside & upswing & uptick \\
& & & & \\
\hline \hline
\end{tabular}


TABLE A8

NEGATIVE MODIFIERS

\begin{tabular}{ccccc}
\hline \hline & & & & \\
adverse & back & below & constrained & contract \\
contracting & contraction & cooling & correction & dampen \\
damping & decelerated & decline & declined & declines \\
declining & decrease & decreases & decreasing & deepening \\
depressed & deteriorated & deterioration & diminished & disappointing \\
dislocation & disruptions & down & downbeat & downside \\
drop & dropping & ebbed & erosion & fade \\
faded & fading & fall & fallen & falling \\
fell & insufficient & less & limit & low \\
lower & moderated & moderating & moderation & reduce \\
reduced & reduction & reluctant & removed & restrain \\
restrained & restraining & restraint & resumption & reversed \\
slack & slow & slowed & slower & slowing \\
slowly & sluggish & sluggishness & slumped & soft \\
softened & softening & stimulate & strained & strains \\
stress & subdued & tragic & turmoil & underutilization \\
volatile & vulnerable & wary & weak & weakened \\
weaker & weaker-than-expected & weakness & & \\
& & & &
\end{tabular}

Note: 'stimulate' is denoted as negative since it is used with discussions regarding an economy in a 'downturn'. 